\title{
O Uso da Estratégia WebQuest no Ensino Superior: uma análise de duas experiências
}

\author{
João Batista Bottentuit Junior, UFMA, jbbj@ufma.br
}

Clara Pereira Coutinho, UMINHO, ccoutinho@ie.uminho.pt

\begin{abstract}
Resumo. Neste artigo apresentamos os resultados de duas experiências pedagógicas desenvolvidas no ensino superior com a metodologia WebQuest. As amostras foram compostas por turmas de alunos dos cursos de Licenciatura em Pedagogia e Bacharelado em Ciências Contábeis. As propostas de atividades feitas a ambas as turmas foram distintas, uma vez que os objetivos foram aferir a aceitação e o envolvimento dos alunos numa perspectiva de produção, num caso, e de utilização, no outro, da metodologia WebQuests em contexto educativo. Os resultados mostram que as estratégias foram bem recebidas pelos alunos em ambas os casos, proporcionando a aquisição e desenvolvimento de um conjunto de competências e habilidades diferenciadas ao nível da pesquisa, análise, trabalho de grupo, etc., que são tão importantes no contexto da sociedade em que vivemos.
\end{abstract}

Palavras Chave: WebQuest, Tecnologias, Estratégias de Ensino, Internet

\begin{abstract}
This article presents the results of two teaching experiments developed in higher education with the WebQuest methodology. The samples were composed of groups of students of Pedagogy and Bachelor of Science in Accounting. The proposed activities made to both classes were distinct, since the goals were to assess the acceptance and involvement of students in a production perspective, in one case and use, on the other, the methodology WebQuests in an educational context. The results show that strategies were well received by students in both cases, providing the acquisition and development of a set of skills and abilities to differentiated level of research, analysis, group work, etc. That are so important in the context of society in which we live.
\end{abstract}

Keywords: WebQuest, Technology, Teaching Strategies, Internet

\section{Introdução}

A Internet é um mar de informações que está em constante mutação, povoando-se, a cada segundo, com novas páginas e novos conteúdos, que podem ser acessados de forma fácil e rápida. Estas informações estão disponíveis nos mais diversos formatos (txt, doc, jpg, gif, $p d f$, $m p 3$, avi, etc.), bem como, nas mais diversas fontes (sites, bibliotecas digitais, wikis, bases de dados, repositórios, periódicos eletrônico, etc.). March (1998: s/p) define a Internet como "a maior enciclopédia do mundo" e, neste sentido, ao realizar as suas pesquisas o utilizador poderá desviar-se do foco, ou mesmo como refere Dias (2000: 151) que "a flexibilidade dos ambientes hipertextos pode conduzir à sobrecarga cognitiva e ao surgimento de problemas de navegação", sendo este aspecto responsável por uma área crítica [...] dos hipertextos educacionais, denominado por desorientação (CONKLIN, 1987), e pelo fenômeno de perdido no hiper-espaço (EDWARDS e HARDMAN, 1989). Outra situação bastante comum é o fato de que pela variedade de informações existentes na Internet o aluno não tem a 
preocupação de analisar e refletir sobre a informação ali contida, fato este que inviabiliza a construção do conhecimento.

Neste sentido é preciso que os educadores reflitam sobre as estratégias de utilização dos recursos na Web para que seus alunos consigam transformar informação em conhecimento e não apenas reproduzam ideias, conceitos e conteúdos já existentes na rede. Silva (2006: p.44) afirma que "a WebQuest irá orientar a navegação do estudante na grande rede de computadores, a fim de se obter a construção e reconstrução de conhecimentos ali encontrados". Desta forma, as estratégias de pesquisas orientadas na Web, tornam-se muito importantes no processo de ensino e aprendizagem, pois guiam os alunos nos caminhos e fontes mais adequados, visto que a facilidade de publicação de informações na rede favorece a existência de muitos conteúdos de origem duvidosa, ou mesmo sem comprovação científica.

\section{Metodologia WebQuests}

A etimologia da palavra WebQuest remete-nos para a soma de duas palavras, ou seja, Web (rede de hiperligações) e Quest (questionamento, busca ou pesquisa). O conceito da WebQuest surgiu em Fevereiro de 1995, na San Diego State University (SDSU), pelo professor Bernard Dodge e seu colaborador (ex-aluno de graduação) Thomas March , no âmbito das atividades propostas na disciplina EDTEC 596, "Interdisciplinary Teaching with Technology"1. Esta estratégia educativa concretiza-se em atividades orientadas para a pesquisa em que toda ou quase toda a informação se encontra na Web, conceito por vezes traduzido como Aventura na Web ou Desafio na Web (CARVALHO, 2003).

Segundo Dodge (1999), Bottentuit Junior, Alexandre e Coutinho (2006) e ainda Cruz, et al. (2007) as WebQuests são constituídas por seis componentes: introdução ao tema a tratar, devendo ser motivador, tarefa que deverá ser desafiante e executável, processo na qual o aluno deverá se orientar para realizar a tarefa, os recursos disponíveis na Web para produção do conhecimento, a avaliação que fornece ao aluno os indicadores qualitativos e quantitativos, a conclusão, que deverá propor um desfecho relembrando os objetivos da atividade e também uma pista para pesquisas ou atividades futuras na mesma temática, e, por último, a página do professor, que fornece explicações sobre o conceito da WebQuest, bem como a forma como esta estratégia deve ser trabalhada/utilizada. Esta estrutura bem delineada é que faz com que uma WebQuest seja diferente de um site educativo qualquer.

No entanto, existem algumas definições sobre a WebQuest que variam de acordo com a perspectiva de cada autor, sendo oportuno, neste sentido, vale apena apresentar algumas definições que servirão de base para uma análise mais profunda do que é uma verdadeira WebQuest, seus elementos constitutivos, funções e objetivos na aprendizagem.

A WebQuest é uma atividade didática, estruturada de forma que os alunos se envolvam no desenvolvimento de tarefas de investigação, utilizando os recursos da Internet. Ou seja, são atividades preparadas pelos docentes, onde a maioria dos recursos para resolver as tarefas podem ser encontrados na Internet (ABAR \& BARBOSA, 2008). Contudo, nos casos em que o assunto trabalhado não possui uma riqueza de referências na Internet, podem ser associados materiais impressos, bem como ser o professor a desenvolver novos materiais para disponibilizar na Web.

Costa (2008: p.40) afirma que a WebQuest é uma atividade "que apela ao desenvolvimento de competências mais importantes do que conhecimentos factuais, como a

\footnotetext{
${ }^{1}$ Ensino Interdisciplinar com Tecnologias
} 
tomada de decisão, a argumentação, a avaliação e ainda implica num processo de investigação e transformação da informação obtida". Segundo Couto (2004: p.34), a WebQuest "é um instrumento de aprendizagem, centrado na resolução de um problema, que pode ser visto como uma atividade que permite ao aluno a liberdade de aprender com a utilização de múltiplos recursos, que podem estar online ou não".

Para Viseu e Carvalho (2003: p.519), as WebQuests são "como que um desafio que se coloca aos alunos, que para o resolverem, transformam a informação disponibilizada num produto final e comunicam aos outros colegas". Para Guimarães (2005: p.25), a WebQuest "utiliza o potencial da Web para motivar os alunos através do uso de recursos reais, podendo o produto final realizado pelos mesmos ser enviado por e-mail ou apresentado aos colegas e ao professor para avaliação e feedback". Já Carvalho (2007: p.322) reforça que "é muito importante que no final, os alunos apresentem o trabalho à turma, porque desenvolvem a capacidade de expor, habituam-se a submeter-se a crítica dos pares e professores e habituamse a criticar o trabalho dos colegas".

Dodge (1995), no seu site, afirma que "Tens of thousands of teachers have embraced WebQuests as a way to make good use of the internet while engaging their students in the kinds of thinking that the 21 st century requires" ${ }^{2}$.

As atividades de uma WebQuest podem ser realizadas em grandes grupos ou em pequenos grupos. A estratégia também foi desenhada para que os alunos pudessem rentabilizar o tempo em atividades que lhes permitissem transformar informação em conhecimento, nos níveis de domínio cognitivo mais avançados (higher order thinking skills). As tarefas das WebQuests são baseadas na taxonomia da aprendizagem ativa proposta por Bloom et al. (1956). Como exemplo destes níveis de domínio cognitivo, temos: a análise, a síntese, a avaliação, o conhecimento, compreensão e aplicação.

March $(2000,2004)$ refere, ainda, que o modelo WebQuest surgiu da necessidade que os professores sentiam de ajudar os alunos a usar as informações adquiridas na Web, para construírem significados em tópicos complexos do mundo real. Neste sentido, "a welldesigned WebQuest uses the power of the Internet and a scaffolded learning process to turn research-based theories into dependable learning-centered practices." ${ }^{3}$ (March, 2004: p.2).

Para Carvalho (2003), uma WebQuest é uma proposta metodológica de trabalho, concebida e implantada por professores para ser resolvida por alunos, sendo que a informação com que os alunos interagem é proveniente, em parte ou na totalidade, de recursos disponíveis online.

Silva (2006: p.44) afirma que "as WebQuests têm a virtude da simplicidade e são ricas para dimensionar os usos educacionais da Internet, com fundamento em aprendizagem colaborativa e processos investigação na construção do saber". Por outro lado, as WebQuests constituem uma forma de ensinar os professores a utilizar a Internet com criatividade e consciência. Neste sentido, esta estratégia funciona como uma investigação orientada, na qual algumas ou todas as informações com as quais os aprendizes interagem são originadas de recursos da Internet (DODGE, 1995).

As WebQuests são atividades de grupo e, como tal, devem favorecer a cooperação dos alunos. Fernandes \& Rodrigues (1995) afirmam que o trabalho em grupo permite que os

\footnotetext{
${ }^{2}$ Dezenas de milhares de professores abraçaram WebQuests como uma maneira de fazer bom uso da internet ao engajar os seus alunos para o tipo de pensamento que o século 21 exige.

${ }^{3}$ Uma WebQuest bem concebida usa o poder da Internet no desenvolvimento do processo de aprendizagem para transformar teorias baseadas na investigação sobre as práticas seguras de aprendizagem centrada.
} 
alunos experimentem, comparem, troquem experiências, discutam entre si e com o professor, comuniquem as suas idéias aos seus pares, tornando-os progressivamente autônomos e cooperantes.

O trabalho colaborativo é um dos princípios da WebQuest, pois pretende modificar o uso individualista do computador para um formato mais participativo, onde todos colaboram para resolver o problema de cada tarefa. Segundo Dodge (1995:s/p), "as WebQuests estão fundadas na convicção de que aprendemos mais e melhor com os outros, e não individualmente. Aprendizagens mais significativas são resultados de atos de cooperação". Vygotsky (2005) afirma ainda que uma criança se puder aprender com auxílio de outro indivíduo, terá um ritmo de desenvolvimento mais acelerado que outra criança que tiver que fazê-lo sozinha. No entanto, Dodge $(1995 ; 1997)$ afirma, ainda que a WebQuest pode também ser planejada para ser utilizada de forma individual em situações de ensino a distância ou em ambiente de bibliotecas.

\section{Atividade de WebQuest com Alunos do Curso de Graduação em Ciências Contábeis}

A primeira amostra a utilizar a metodologia WebQuest foi constituída por alunos do curso de Ciências Contábeis da Faculdade do Maranhão na cidade de São Luís (Brasil). Apesar de não existirem muitas experiências de utilização da estratégia WebQuest no ensino superior, pensamos ser importante perspectivar contextos de dinâmicas de utilização desta estratégia educativa neste nível de ensino.

A WebQuest intitulada "WebQuest sobre as áreas da Contabilidade" foi concebida para os conteúdos da disciplina de Atividades Complementares I. Esta unidade curricular é lecionada no $1^{\circ}$ período do curso de Ciências Contábeis e possui uma carga horária total de 40 horas aula, com apenas um encontro semanal de 2 (duas) horas aula. Esta unidade curricular teve como objetivo principal, introduzir conceitos básicos sobre a contabilidade, os ramos de atuação profissional, assim como preparar os estudantes para ingresso no mercado de trabalho, entrevistas de emprego, técnicas de estudo e aprendizagem e organização da vida universitária.

No fim da primeira unidade didática que versava sobre os conceitos da contabilidade iniciamos as sessões dedicadas à metodologia de ensino baseada na WebQuest e seus potenciais educativos.

A primeira sessão (13 de Agosto de 2009) serviu para que os alunos ficassem a conhecer a filosofia da WebQuest, seus objetivos e vantagens pedagógicas. Para isso, foi utilizada uma apresentação em Power Point com conceitos e exemplos da estratégia. Após a explicação, foi apresentado o Portal das WebQuests e as suas diversas secções, onde os alunos poderiam buscar mais informações e explicações sobre a metodologia. Foi ainda solicitado, como trabalho de casa, a leitura complementar de dois artigos sobre as WebQuest escolhidos livremente na seção "Artigos e Teses" disponível no Portal Educacional de WebQuests em Língua Portuguesa ${ }^{4}$.

Na segunda sessão (26 de Agosto de 2009), serviu para aferirmos se os alunos realmente tinham compreendido os objetivos da estratégia WebQuest, foi realizado um debate onde eles equacionaram os pontos fortes e fracos desta metodologia, bem como foi solucionado algumas dúvidas que os alunos tinham sobre a aprendizagem através desta metodologia.

\footnotetext{
${ }^{4}$ www.portalwebquest.net

V. $8 \mathrm{~N}^{\mathrm{o}} 3$, dezembro, 2010
} 
Na terceira sessão, foi apresentada a estratégia intitulada "WebQuest Sobre as Áreas da Contabilidade". Para resolverem a WebQuest ${ }^{5}$, os alunos deveriam pesquisar sobre as áreas da contabilidade com o objetivo de criar uma apresentação convincente que pudessem ajudar o personagem "Lucas" a escolher um dos ramos da contabilidade para prosseguir ao nível de pós-graduação.

Para a concepção da WebQuest foram considerados todos os aspectos de qualidade de uma WebQuests. Portanto, oferecemos na página de entrada as informações sobre: o nível etário, autoria, contato, data de criação e atualização do site. A introdução foi breve e remetia a um problema no qual os alunos deveriam solucionar em conjunto. A tarefa exigiu o trabalho em equipe, a criatividade, a investigação na $W e b$ e principalmente a criação de um produto final. Os recursos foram variados e suficientes para a resolução da tarefa. A avaliação ofereceu indicadores quantitativos e qualitativos relacionados aos aspectos desenvolvidos pelos alunos na tarefa. E por fim a conclusão ofereceu um desfecho e indicou pistas para outras investigações.

Ao realizarem a tarefa, os alunos tiveram a oportunidade de explorar as competências informáticas para o desenvolvimento dos slides, a capacidade de trabalho em equipe a criatividade e ainda a oralidade durante as apresentações.

\subsection{Resultados Obtidos com os Alunos de Graduação em Ciências Contábeis}

Para aferirmos acerca da satisfação dos alunos sobre a metodologia WebQuest, bem como as dinâmicas de utilização do portal foi administrado um pequeno questionário dividido em duas seções, sendo: a) a primeira composta de duas questões sobre dados pessoais da amostra e; b) uma segunda seção dedicada a opiniões sobre a metodologia WebQuest e sobre o Portal que acessaram para realizar a atividade. O questionário incluía questões do tipo: dicotômicas, de múltipla escolha e abertas. A aplicação do questionário ocorreu após o encerramento da atividade no mês de Setembro de 2009.

A amostra foi composta de 34 (trinta e quatro) alunos do curso de Graduação em Ciências Contábeis, sendo $58 \%$ do sexo masculino e $42 \%$ do sexo feminino. Com relação à faixa etária $34 \%$ estavam entre os 18 e 20 anos, $26 \%$ entre 21 e 23 anos, $12 \%$ entre os 24 e 26 anos e $28 \%$ com idade superior a 27 anos.

Apesar da estratégia WebQuest ainda encontrar-se em processo de divulgação, ou seja, ainda não é conhecida em todas as áreas e níveis de ensino, quando questionamos os alunos se já tinha ouvido falar nesta metodologia antes da apresentação em sala de aula (na disciplina Atividades Complementares I), apenas 6\% (dois alunos) já haviam utilizado esta metodologia em outros contextos educativos, enquanto $94 \%$ dos alunos, nunca tinham ouvido falar em WebQuests.

Com relação à opinião sobre a estratégia WebQuest, em todos os aspectos, mais da metade da turma considerou que a aprendizagem se deu de uma forma mais divertida, sem a ajuda do professor; relataram ainda que aprenderam a utilizar a Internet de forma mais eficiente já que aprenderam a pesquisar na Web (ver tabela 1)

\section{\begin{tabular}{|l|l|l|}
\hline O que você achou da estratégia & Concordo & Discordo
\end{tabular} WebQuest?}

\footnotetext{
${ }^{5}$ http://www.portalwebquest.net/webquestcontabilidade.htm

V. $8 \mathrm{~N}^{\mathrm{o}} 3$, dezembro, 2010
} 


\begin{tabular}{|c|c|c|}
\hline $\begin{array}{l}\text { O que você achou da estratégia } \\
\text { WebQuest? }\end{array}$ & Concordo & Discordo \\
\hline Aprendi de forma mais divertida. & $88 \%$ & $12 \%$ \\
\hline $\begin{array}{l}\text { Aprendi sem a ajuda do professor (forma } \\
\text { mais autônoma). }\end{array}$ & $76 \%$ & $24 \%$ \\
\hline $\begin{array}{l}\text { Aprendi a utilizar a Internet de forma } \\
\text { mais eficiente. }\end{array}$ & $56 \%$ & $44 \%$ \\
\hline Aprendi a pesquisar. & $68 \%$ & $32 \%$ \\
\hline Aprendi a trabalhar em grupo. & $59 \%$ & $41 \%$ \\
\hline
\end{tabular}

Tabela 1 - Opiniões Sobre a Estratégia WebQuest

O último bloco de perguntas era do tipo aberta, e teve como objetivo aferir a opinião dos alunos relativamente à qualidade do portal das WebQuest que foi uma das atividades iniciais realizadas pelos alunos. Quando questionados sobre o que acharam do Portal das WebQuests, a maioria utilizou adjetivos como: educativo (6), intuitivo (5), excelente (4), didático (4), interessante (3), bom (3), diferente (2), auto-explicativo (2), leve (2), moderno (2), atual (1).

Pedimos ainda que os alunos indicassem algumas das potencialidades de utilização do portal, sendo muitas as sugestões dadas pelos estudantes:

"Um espaço de informação para alunos e professores sobre uma forma de ensinar e aprender através das páginas da Internet”. A5

"Considero este portal como um ambiente online de auxílio a escolas e universidade que queiram utilizar as WebQuests em suas práticas de sala de aula". A7

"Um excelente site para aprendizagem nesta sociedade informatizada que necessita diariamente das informações da rede e nem sempre sabemos como utilizar de maneira adequada". A12

"Este portal poderá ser utilizado para trocar experiências entre alunos e professores sobre as atividades com WebQuests". A26

"Na minha opinião o portal é bastante informativo e serviu para que eu pudesse conhecer esta nova metodologia e ainda me surpreendi com a grande quantidade de experiências realizadas em vários países do mundo". A32

A partir das respostas obtidas podemos concluir que os alunos equacionam dinâmicas voltadas para a informação e trocas de experiências entre os utilizadores da metodologia WebQuest, bem como um ponto de sugestão para outros professores sobre as formas de aprender e ensinar com auxílio aos diversos recursos disponíveis na rede. 


\section{Atividade de WebQuest com Alunos do Curso de Graduação em Pedagogia}

A segunda amostra que trabalhou com a metodologia WebQuest foi formada por alunos do Curso de Licenciatura em Pedagogia da Universidade Federal do Maranhão na cidade de São Luís (Brasil).

A amostra foi constituída por 62 (sessenta e dois) alunos que cursavam a disciplina Educação Trabalho e Educação durante os meses de Julho e Agosto de 2010 em período intensivo de férias. Esta disciplina possui uma carga horária de $60 \mathrm{hr}$ aula com atividades teóricas e práticas, em período regular a mesma deverá ser ministrada com encontros semanais de $2 \mathrm{hrs}$ cada, no entanto como foi ofertada em período intensivo as aulas ocorreram durante 3(três) semanas com 4 hrs aula por dia.

O objetivo desta unidade curricular é oferecer aos alunos uma visão teórica e prática sobre as relações entre educação e trabalho, educação e tecnologia e trabalho e tecnologia. Neste sentido cada semana foi trabalhada uma destas temáticas, sendo que a última semana trabalhou-se com o eixo educação e tecnologias. Para consecução dos objetivos da disciplina selecionou-se algumas ferramentas da Web 2.0 para trabalharmos e discutirmos tais como o Blog, o Wiki e o Podcast, e por fim algumas estratégias de ensino baseadas na Web tais como o caça ao tesouro e a WebQuest.

$\mathrm{Na}$ primeira secção sobre as metodologias baseadas na Web dedicou-se uma aula teórica sobre o conceito das WebQuests, sua estrutura, componentes, duração bem como alguns exemplos práticos de utilização da metodologia em outros contextos e seus respectivos benefícios a nível educacional. Foi ainda apresentado aos alunos o Portal das WebQuests em Língua portuguesa que contem um importante acervo sobre esta metodologia em língua lusófona e poderia servir como fonte de pesquisa e aprofundamento teórico e prático para todos os alunos interessados na estratégia.

Após esta primeira secção os alunos se dividiram em grupos de trabalho e o objetivo da atividade planejada foi a construção de uma WebQuest. O suporte para a construção das estratégias foi o software Power Point, pois não havia tempo hábil para a construção em outros suportes mais sofisticados como, por exemplo, o Google Sites. Os trabalhos deveriam conter todas as componentes da WebQuest e a tarefa deveria ser refletida num produto tal como um folheto, artigo, reportagem, cartaz, etc. O prazo para a construção dos trabalhos foi de 2 (dois) dias e ao final da atividade todos os integrantes da equipe deveriam apresentá-lo de forma oral perante as outras equipes.

Após a apresentação dos trabalhos foi administrado um questionário de múltipla escolha (Agosto de 2010) para avaliarmos percepções em relação à WebQuest, opinião perante as dinâmicas do trabalho de grupo, cooperação e colaboração, atividades de pesquisa, uso do computador para a consecução da atividade. Algumas das questões utilizadas para o estudo foram adaptadas de um questionário utilizado numa investigação em nível de mestrado realizada por Costa (2008).

\subsection{Apresentações dos Resultados com os Alunos de Licenciatura em Pedagogia}

Da amostra inicial de 62 (sessenta e dois) alunos só conseguimos obter 54 (cinquenta e quatro) questionários respondidos visto que 2 (dois) alunos desistiram e 6 (seis) não devolveram o questionário. Os dados foram tratados logo no mês de Agosto de $2010 \mathrm{com}$ auxílio do software Excel. 
Dos participantes deste estudo $34 \%$ eram do sexo masculino, enquanto que $67 \%$ eram do sexo feminino. Com relação à faixa etária $4 \%$ estavam entre os 18 e 20 anos, 36\% entre 21 e 23 anos, $53 \%$ entre os 24 e 26 anos e $7 \%$ com idade superior a 27 anos.

Em relação ao trabalho em grupo a grande maioria acredita que em grupo trabalha-se de uma forma mais descontraída, podendo distribuir e maximizar as tarefas bem como partilhar conhecimentos e idéias com os colegas (ver tabela 2)

\begin{tabular}{|l|c|c|}
\hline & f & $\%$ \\
\hline Melhora o processo de aprendizagem & 14 & $26 \%$ \\
\hline Trabalha-se de forma mais descontraída & 43 & $80 \%$ \\
\hline É melhor para distribuir e maximizar as tarefas & 50 & $93 \%$ \\
\hline Há mais ajuda entre os componentes da equipe & 12 & $22 \%$ \\
\hline Permite a partilha de conhecimentos e ideias com os colegas & 51 & $94 \%$ \\
\hline
\end{tabular}

Tabela 2 - Questões acerca do trabalho de grupo $(n=54)$

As competências de pesquisa na Web são fundamentais nos dias de hoje, afinal de contas vivemos numa sociedade onde a informação se tornou primordial e a fonte mais consultada atualmente é justamente a Web, pois permite a visualização em múltiplos formatos enriquecendo desta forma a aprendizagem. Quando questionados acerca dos aspectos relacionados às pesquisas os inquiridos sentem mais dificuldades em escolher os sites bem como se distraem com informações não relevantes (ver tabela 3)

\begin{tabular}{|l|c|c|}
\hline & f & $\%$ \\
\hline Falta de conhecimentos para utilizar a Web & 5 & $9 \%$ \\
\hline Dificuldade em escolher os sites & 22 & $41 \%$ \\
\hline Falta de qualidade da informação obtida & 6 & $11 \%$ \\
\hline Distrair-me com informação que não é relevante & 16 & $30 \%$ \\
\hline
\end{tabular}

Tabela 3 - Questões acerca da atividade de pesquisa $(\mathrm{n}=54)$

Ao construir uma WebQuest os participantes envolvidos adquirem competências e habilidades ao longo do processo e neste sentido gostaríamos de verificar até que pontos os participantes conseguiram perceber estes ganhos ao construírem as suas próprias WebQuests com as recomendações repassadas ao longo das aulas. Com relação aos ganhos obtidos ao construírem as WebQuest a grande maioria afirma que aprenderam novas formas de ensinar e aprender com os recursos da Web, a valorizar as ideias fornecidas pelos colegas de equipe, aprenderam a pesquisar outras fontes de pesquisa na Web, exercitaram a criatividade, trabalharam de forma colaborativa, sentiram-se satisfeitos com o trabalho final (ver tabela 4).

\begin{tabular}{|l|c|c|}
\hline & f & $\%$ \\
\hline Aprendi novas formas de ensinar e aprender utilizando os recursos da Web & 46 & $85 \%$ \\
\hline Não considero muito eficaz a proposta pedagógica da WebQuest & 5 & $9 \%$ \\
\hline Aprendi a valorizar as ideias fornecidas pelos meus colegas de equipe & 43 & $80 \%$ \\
\hline Aprendi a pesquisar outras fontes de pesquisa na Web & 38 & $70 \%$ \\
\hline
\end{tabular}

V. $8 \mathrm{~N}^{\mathrm{o}} 3$, dezembro, 2010 


\begin{tabular}{|l|c|c|}
\hline & f & $\%$ \\
\hline Exercitei a criatividade ao longo do desenvolvimento das atividades & 36 & $67 \%$ \\
\hline Trabalhei de forma colaborativa & 42 & $78 \%$ \\
\hline Senti-me satisfeito com o trabalho final & 34 & $63 \%$ \\
\hline
\end{tabular}

Tabela 4 - Questões acerca do desenvolvimento da WebQuest $(n=54)$

Ao todo foram desenvolvidas 10 (dez) WebQuest e a grande maioria das estratégias estavam relacionadas com a cidade de São Luís e sua cultura popular. Outros assuntos valorizados na construção das estratégias estavam à preservação do meio ambiente, a construção de mapas, o aquecimento global, o turismo e a língua inglesa. Alguns dos trabalhos realizados pelos alunos estão disponíveis na figura 1.
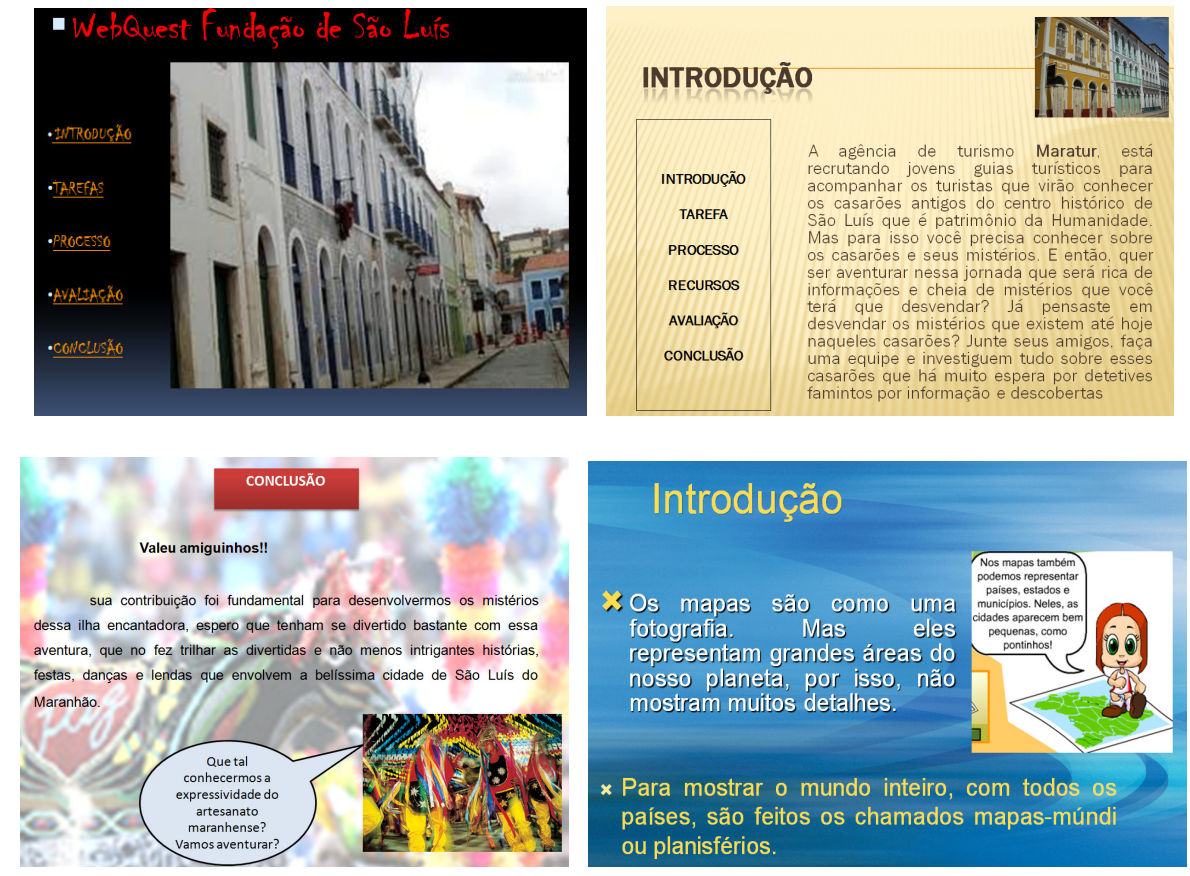

Figura 1 - Algumas das WebQuests realizadas pelos alunos

A atividade de produzir uma WebQuest é algo que exige dos envolvidos a atenção, a criatividade, a habilidade de trabalhar em grupo, de pesquisa, de construção lógica de tarefas e processos de realização em fases, bem como a seleção de recursos significativos e a definição de critérios adequados de avaliação. Ao longo deste percurso os envolvidos vão adquirindo estas competências e favorecem os alunos com estratégias inovadoras que tentam aliar a grande quantidade de recursos disponíveis na web ao ensino e aprendizagem dos conteúdos de uma forma mais ativa e lúdica.

\section{Conclusões}

A metodologia WebQuest vem sendo utilizada em larga escala em todo o mundo, no entanto, no ensino de nível superior ainda são escassas as experiências o que faz com que os estudos apresentados neste artigo constituam um contributo e, ao mesmo tempo, um incentivo para que outros professores do ensino superior valorizem esta estratégia como forma de 
proporcionarem aos seus alunos formas de aprendizagem ativa, colaborativa e, principalmente, alinhada com a utilização de recursos atualizados e fiáveis.

Em ambas as atividades, observamos uma grande motivação dos alunos para com a descoberta de uma nova possibilidade de aprender servindo-se dos recursos mais utilizados pelos alunos e professores nos dias atuais, ou seja, a Internet.

Em especial, as dinâmicas e estratégias construídas pelos alunos do Curso de Pedagogia constituem uma grande mais-valia na medida em que estas podem perfeitamente ser utilizadas por outros docentes que pretendam utilizar as WebQuests em contexto de sala de aula.

\section{Referências}

ABAR, C.A.A.P.; BARBOSA, L.M. WebQuest, um desafio para o professor: uma solução inteligente para o uso da Internet. São Paulo: Avercamp. 2008.

BLOOM, B.S. et al. Taxonomy of Educational Objectives: The classification of Educational Goals. Handbook I: Cognitive domain. NY: David McKay. 1956.

BOTTENTUIT JUNIOR, J. B.; ALEXANDRE, D.S.; COUTINHO, C. P. M-learning e WebQuests: as novas tecnologias como recurso pedagógico. Revista Educação \& Tecnologia, Belo Horizonte: Centro Federal de Educação Tecnológica de Minas Gerais, v. 11, pp. 55-61. 2006.

CARVALHO, A. A. A. WebQuest: um desafio para professores. In Albano Estrela \& Júlia Ferreira (orgs), XII Colóquio da AFIRSE/AIPELF: A Formação de Professores à Luz da Investigação. Lisboa: AFIRSE, vol. II, 732-740. 2003.

CARVALHO, A. A. A. Rentabilizar a internet no ensino básico e secundário: dos recursos e ferramentas online aos LMS. Sísifo: revista de ciências da educação. Faculdade de Psicologia e de Ciências da Educação. Lisboa: Universidade de Lisboa. 2007. Disponível em: http://repositorium.sdum.uminho.pt/bitstream/1822/7142/1/sisifo 03PT02.pdf. Acedido a 04/03/2009.

CONKLIN, J. Hypertext: An Introduction and Survey. IEEE Computers. 20 (9), 17-41. 1987

COSTA, I. M. S. A WebQuest na Aula de Matemática: um estudo de caso com alunos do $10^{\circ}$ ano de escolaridade. Dissertação de Mestrado em Educação com Especialização em Tecnologia Educativa. Braga: Universidade do Minho, Instituto de Educação e Psicologia. 2008

COUTO, M. S. A Eficácia da WebQuest no Tema "Nós e o Universo" usando uma Metodologia numa Perspectiva CTS: um estudo de caso com alunos do $8^{\circ}$ ano de escolaridade. Dissertação de Mestrado em Física, na Área de Especialização em Ensino. Braga: Universidade do Minho. 2004

CRUZ, S.; BOTTENTUIT JUNIOR, J. B.; COUTINHO, C. P. ; CARVAlHO, A. A. A. O Blogue e o Podcast como Resultado da Aprendizagem com WebQuests. Actas da V Conferência Internacional de Tecnologias de Informação e Comunicação na Educação: Desafios 2007/ Challenges 2007. pp. 893-904. Braga: Universidade do Minho. 2007.

DODGE, B. Some Thoughts about WebQuests. 1995. Disponível em: http://WebQuest.sdsu.edu/about_WebQuests.html Acedido a 09/02/2009.

DODGE, B. Building Blocks of a WebQuest. 1997. Disponível em: http://projects.edtech.sandi.net/staffdev/buildingblocks/p-index.htm Acedido a 09/02/2009. 
DODGE, B. Creating a Rubric for a Given Task. 1999. Disponível em: http://projects.edtech.sandi.net/staffdev/tpss99/rubrics/rubrics.html. Acedido em $10 / 02 / 2009$

EDWARDS, D. e HARDMAN, L. Lost in Hyperspace: Cognitive Mapping and Navigation in a Hypertext Environment. In R. McALEESE e C. GREEN (Eds.), Hypertext: Theory into Practice. Oxford: Intellect Limited. 1989.

FERNANDES, M.; RODRIGUES, A. Novas orientações em educação Matemática. In Carvalho, Adalberto e tal (1995). Novas metodologias em educação. Porto: Porto Editora. Vol VIII. P.411-436. 1995.

GUIMARÃES, D. A Utilização da WebQuest no Ensino da Matemática: aprendizagem e reacções dos alunos do $8^{\circ}$ ano. Dissertação de Mestrado em Educação, na área de especialização de Tecnologia Educativa. Braga: Universidade do Minho. 2005.

MARCH, T. Why WebQuests?, an introduction. 1998. Disponível em: http://www.tommarch.com/writings/intro_wq.php. Acedido a 09/02/2009.

MARCH, T. Tips on choosing and assessing WebQuests. 2000. Disponível em: http://www.infotoday.com/MMSchools/oct00/march.htm Acedido a: 09/02/2009.

MARCH, T. WebQuest: The Fulcrum for Systemic Curriculum Improvement. 2004. Disponível

em: http://center.ouregon.edu/ISRE/NECC2004/handout_files_live/KEY_106238/Webques t_fulcrum_necc.pdf Acedido a 12/02/2009

SILVA, K. X. S. WEBQUEST: uma metodologia para pesquisa escolar por meio da Internet. Dissertação de Mestrado em Educação. Brasília: Universidade Católica de Brasília. 2006.

VISEU, F.; CARVAlhO, A. A. Percepções de alunos da Licenciatura em Ensino de Matemática sobre concepção e implementação de WebQuests. In P. Dias e C. V. Freitas (Orgs.), atas da III Conferência Internacional de Tecnologias de Informação e Comunicação na Educação: Braga: Universidade do Minho, pp. 509 - 519. 2003.

VYGOTSKY, L. S. Pensamento e Linguagem. 3. ed. São Paulo: Martins Fontes. 2005. 